\title{
Produção de mudas de Rheedia acuminata com adição de cama de aviário ao
}

\section{substrato}

\author{
Production of seedlings of Rheedia acuminata with addition of poultry litter to the substrate \\ Producción de plántulas de Rheedia acuminata con adición de cama de pajarera al substrato
}

\author{
Nouglas Veloso Barbosa Mendes \\ ORCID: https://orcid.org/0000-0003-4873-3206 \\ C\&N Serviços Agroambientais Ltda, Brasil \\ Agritech Semiárido Agricultura Ltda, Brasil \\ E-mail: nouglasmendes@hotmail.com \\ Walnice Maria Oliveira do Nascimento \\ ORCID: https://orcid.org/0000-0002-1558-4059 \\ Empresa Brasileira de Pesquisa Agropecuária, Brasil \\ E-mail: walnice.nascimento@embrapa.br \\ Denise de Castro Lima \\ ORCID: https://orcid.org/0000-0001-5313-7586 \\ Instituto Centro de Ensino Tecnológico, Brasil \\ E-mail: dennisedecastro@gmail.com
}

\begin{abstract}
Resumo
Rheedia acuminata é espécie frutífera nativa da Amazônia com potencial para consumo in natura. O objetivo do trabalho foi estudar a produção de mudas com adição de matéria orgânica utilizando diferentes concentrações de cama de aviário ao substrato. $\mathrm{O}$ experimento foi conduzido no viveiro de produção de mudas do Laboratório de Frutíferas da Embrapa Amazônia Oriental, Belém, Pará, Brasil. Adotou-se o delineamento inteiramente casualizado, os tratamentos constaram das seguintes misturas do solo com cama de aviário $(0 \%, 10 \%, 20 \%, 30 \%$ e $40 \%)$, com quatro repetições de dez mudas por parcela. Para a caracterização do crescimento das mudas foram realizadas as seguintes avaliações: altura, diâmetro do coleto, número de folhas, massa seca da parte aérea, massa seca da raiz, massa seca total e índice de qualidade de Dickson. Os parâmetros morfológicos e o índice de qualidade de Dickson observados nas mudas foram afetados pela composição do substrato. Conclui-se que para produção de mudas de Rheedia acuminata, vigorosas e com capacidade de serem levadas a campo, deve ser feita adição de $20 \%$ a $30 \%$ de cama de aviário ao solo para a composição do substrato.
\end{abstract}

Palavras-chave: Bacurizinho rugoso; Matéria orgânica; Espécie nativa; Frutífera; Amazônia.

\begin{abstract}
Rheedia acuminata is a fruit species native to the Amazon with potential for fresh consumption. The objective of this work was to study the production of seedlings with the addition of organic matter using different concentrations of poultry litter to the substrate. The experiment was carried out in the seedling production nursery of the Fruit Laboratory of Embrapa Amazônia Oriental, Belém, Pará, Brazil. A completely randomized design was adopted, the treatments consisted of the following mixtures of soil with aviary bedding $(0 \%, 10 \%, 20 \%, 30 \%$ and $40 \%)$, with four repetitions of ten seedlings per plot. To characterize the seedling growth, the following evaluations were performed: height, stem diameter, number of leaves, shoot dry mass, root dry mass, total dry mass and Dickson quality index. Morphological parameters and Dickson quality index observed in seedlings were affected by substrate composition. It is concluded that for the production of Rheedia acuminata seedlings, vigorous and capable of being taken to the field, $20 \%$ to $30 \%$ of aviary bedding should be added to the soil for the composition of the substrate.
\end{abstract}

Keywords: Rough bacurizinho; Organic matter; Native species; Fruitful tree; Amazon.

\section{Resumen}

Rheedia acuminata es una especie frutal nativa del Amazonia con potencial de consumo in natura. El objetivo del trabajo fue estudiar la producción de plántulas con la adición de materia orgánica utilizando diferentes concentraciones de cama de pajarera al sustrato. El experimento se realizó en el vivero de producción de plántulas del Laboratorio de Frutas de Embrapa Amazonia Oriental, Belém, Pará, Brazil. Se adoptó un diseño totalmente aleatorizado y los tratamientos consistieron en las siguientes mezclas de suelo con cama de pajarera $(0 \%, 10 \%, 20 \%$, $30 \%$ y 40\%), con cuatro repeticiones de diez plántulas por parcela. Para caracterizar el crecimiento de las plántulas se realizaron las siguientes evaluaciones: altura, diámetro del cuello, número de hojas, masa seca aérea, masa seca de raíz, masa seca total e índice de calidad de Dickson. Los parámetros morfológicos y el índice de calidad de Dickson observados en las plántulas se vieron afectados por la composición del sustrato. Se concluye que para la producción 
de plántulas vigorosas de Rheedia acuminata, capaces de ser llevadas al campo, se debe hacer la adición de $20 \%$ a $30 \%$ de cama de pajarera al suelo para la composición del sustrato.

Palabras clave: Bacurizinho rugoso; Materia orgánica; Especie nativa; Fructífero; Amazonia.

\section{Introdução}

A Rheedia acuminata Planchon \& Triana - Clusiaceae, é conhecida como bacurizinho rugoso (Pará), bacuri-deespinhos (Amazonas), limãozinho (Mato Grosso), pakoeli e swampoe-pakoeli (Suriname) é uma espécie frutífera de pequeno porte, tendo em média 6 a 10 m de altura, distribuída por toda a Amazônia em estado silvestre, raramente cultivada, pois seus frutos, embora comestíveis, apresentam escasso rendimento da parte comestível (Van den Berg, 1979; Cavalcante, 2010). Em quase todos os meses do ano apresenta flor e fruto, geralmente dois picos de floração e frutificação ao longo do ano (Mendes et al., 2020).

Recentemente tem se notado uma tendência crescente na procura por frutas nativas em diferentes regiões do Brasil, assim, há demanda por frutos da família Clusiaceae (bacuri, achachairu, mangostão, bacupari, bacurizinho rugoso, entre outros), isso faz com que se busquem pesquisas que viabilizem a produção de mudas e estabelecimento dessas plantas no meio agrícola/frutícola nas diferentes regiões do Brasil.

Os estudos com essa espécie visam a sua utilização como porta-enxerto para formar mudas, reduzir a altura e acelerar a produção de frutos das plantas frutíferas que apresentam porte elevado e tem a formação de mudas demorada, como o bacuriparizeiro (Rheedia macrophylla Planchon et Triana), o mangostãozeiro (Garcinia mangostana L.) e o bacurizeiro (Platonia insignis Mart.) que possuem interesse agronômico e valor econômico agregado (Nascimento, Carvalho \& Müller, 2002).

Para que a planta frutífera tenha pleno desenvolvimento na fase adulta onde haverá a produção de frutos é necessário que haja bastante cuidado na produção de mudas, pois mudas sem observância da qualidade podem resultar em árvores de características ruins, assim, podem comprometer a uniformidade do pomar. Dentre os fatores que podem afetar a qualidade das mudas estão: a semente, o substrato e o adubo utilizado, pois estes contribuem para melhor desenvolvimento e sanidade das mudas (Yamanishi et al., 2004).

Os maiores ganhos na produção de mudas frutíferas com redução do custo final ocorrem devido ao volume e o substrato adequado que proporcionam crescimento e produção de mudas de qualidade (Mesquita et al., 2012). E independente se a muda for produzida com a finalidade de comercialização ou para o plantio em pomar próprio é de suma importância atestar sua qualidade para o consumidor final, isso se dá por meio de visualização do estado aparente da muda ou por meio da avaliação nutricional e/ou fitossanitária. A muda de elevada qualidade, com vigor superior e equilíbrio entre a composição da parte aérea e da raiz poderá obter melhor pegamento e sobrevivência ao ser plantada no local definitivo (Lima et al., 2016).

A adição de matéria orgânica no solo para a composição do substrato para a produção de mudas tem se tornado uma realidade, visto que há melhoria na composição físico/químico, na aeração, na manutenção da umidade e isso influi positivamente no desenvolvimento da muda. Algumas pesquisas têm evidenciado a utilização da cama de aviário como fonte de matéria orgânica na composição do substrato para formação de mudas, por exemplo, maracujazeiro (David et al., 2008), taro ou inhame (Oliveira et al., 2008), tamarindeiro (Pereira et al., 2010), pinhão manso (Torres et al., 2011) e açaí-doamazonas (Mendes et al., 2014).

Portanto, o objetivo do trabalho foi verificar a produção de mudas de $R$. acuminata, com adição de diferentes concentrações de cama de aviário ao solo na composição do substrato. 


\section{Metodologia}

O experimento foi conduzido no viveiro de produção de mudas do Laboratório de Frutíferas da Embrapa Amazônia

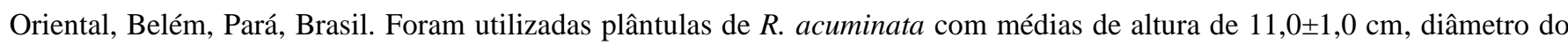
coleto de $1,5 \pm 0,5 \mathrm{~mm}$ e duas folhas. Como recipiente para produção das mudas foi utilizado saco de polietileno preto perfurado, com dimensões de $17 \mathrm{~cm}$ de largura por $27 \mathrm{~cm}$ de comprimento e $0,2 \mathrm{~mm}$ de espessura. $\mathrm{O}$ substrato utilizado foi solo com adição de matéria orgânica na forma de cama de aviário em diferentes concentrações.

$\mathrm{O}$ experimento foi realizado em delineamento inteiramente casualizado, sendo que os tratamentos constaram das seguintes misturas do solo com a cama de aviário $(0 \%, 10 \%, 20 \%, 30 \%$ e $40 \%)$. Com quatro repetições de dez mudas por parcela totalizando, assim, quarenta por tratamento e duzentas mudas avaliadas no experimento. O resultado da análise do solo foi: 16,25 g/Kg de M.O.; 0,05\% de N; 5,5 pH (em água); $276 \mathrm{mg} / \mathrm{dm}^{3}$ de $\mathrm{P}_{2} \mathrm{O}_{5} ; 22 \mathrm{mg} / \mathrm{dm}^{3}$ de $\mathrm{K}_{2} \mathrm{O} ; 5,2 \mathrm{Cmolc} / \mathrm{dm}^{3} \mathrm{de} \mathrm{Ca}^{+2}$; 3,3 Cmolc/ $/ \mathrm{dm}^{3}$ de $\mathrm{Mg}^{+2} ; 0,1 \mathrm{Cmolc} / \mathrm{dm}^{3}$ de alumínio, sendo o mesmo de textura média. Para a cama de aviário foi: $52,43 \mathrm{~g} / \mathrm{kg}$ de nitrogênio; $11,37 \mathrm{~g} / \mathrm{kg}$ de fósforo; $5,37 \mathrm{~g} / \mathrm{kg}$ de potássio e $0,41 \mathrm{~g} / \mathrm{kg}$ de sódio.

As mudas permaneceram em viveiro sob tela tipo sombrite ${ }^{\circledR}$ com $50 \%$ de interceptação luminosa durante o período de avaliação (12 meses). Por ocasião da instalação do experimento foram feitas as seguintes mensurações: altura da parte aérea $(\mathrm{cm})$ com o auxílio de régua metálica graduada, diâmetro do coleto $(\mathrm{mm})$ com auxílio de paquímetro digital e número de folhas (contagem visual). Após a última avaliação do experimento foram retiradas ao acaso cinco mudas de cada parcela dos tratamentos para a determinação das massas; as mesmas foram lavadas para retirar o substrato e, em seguida, separado parte aérea e sistema radicular, acondicionadas as partes em sacos de papel tipo kraft e levadas a estufa de circulação de ar $60 \pm 1^{\circ} \mathrm{C}$ até atingir peso constante, retiradas da estufa e pesadas para a determinação da massa seca da parte aérea, massa seca da raiz e massa seca total, de posse dessas informações foi obtido o índice de qualidade de Dickson (IQD); calculado por meio da fórmula proposta por Dickson, Leaf e Hosner (1960), cuja segue:

$$
\mathrm{IQD}=\frac{\operatorname{MST}(\mathrm{g})}{\frac{\operatorname{Altura}(\mathrm{cm})}{\text { Diâmetro }(\mathrm{mm})}+\frac{\operatorname{MSPA}(\mathrm{g})}{\operatorname{MSR}(\mathrm{g})}}
$$

em que:

$$
\begin{aligned}
& \text { IQD = Índice de qualidade de Dickson; } \\
& \text { MST = Massa seca total; } \\
& \text { MSPA = Massa seca da parte aérea; e } \\
& \text { MSR = Massa seca da raiz. }
\end{aligned}
$$

Os dados foram submetidos a análise de variância pelo teste $\mathrm{F}$ e quando houve significância aplicou-se a regressão polinomial $\left(a+b x+c x^{2}\right)$ utilizando o programa de análises estatísticas Sisvar (Ferreira, 2006).

\section{Resultados e Discussão}

Os resultados da análise de variância revelaram efeitos significativos $(p<0,01)$ das concentrações de cama de aviário no desenvolvimento das mudas de $R$. acuminata para as variáveis altura, diâmetro do coleto, número de folhas, massa seca da parte aérea, massa seca da raiz, massa seca total e para o índice de qualidade de Dickson (Tabela 1). 
Tabela 1. Análise de variância para as variáveis altura (ALT), diâmetro do coleto (DIÂM), número de folhas (NF), massa seca da parte aérea (MSPA), massa seca da raiz (MSR), massa seca total (MST) e índice de qualidade de Dickson (IQD), avaliadas em mudas de Rheedia acuminata, Belém -PA.

\begin{tabular}{cccccccccc}
\hline & & \multicolumn{5}{c}{ Quadrado médio } \\
\cline { 3 - 8 } FV & GL & ALT & DIÂM & NF & MSPA & MSR & MST \\
& & $(\mathrm{cm})$ & $(\mathrm{mm})$ & $(\mathrm{un})$ & $(\mathrm{g})$ & $(\mathrm{g})$ & $(\mathrm{g})$ & IQD \\
\hline CCA & 4 & $132,32^{* *}$ & $2,97 * *$ & $62,22^{* *}$ & $149,25 * *$ & $15,80^{* *}$ & $237,27 * *$ & $3,05^{* *}$ \\
Erro & 15 & 7,19 & 0,41 & 6,56 & 11,87 & 2,68 & 18,26 & 0,44 \\
\hline CV (\%) & & 7,96 & 8,42 & 10,10 & 17,99 & 16,14 & 14,58 & 14,35 \\
Média & 33,71 & 7,64 & 25,37 & 19,16 & 10,15 & 29,31 & 4,62 \\
\hline
\end{tabular}

Teste $\mathrm{F} * *$ significativo a $\mathrm{P}<0,01 ; \mathrm{CCA}=$ cama de aviário e $\mathrm{CV}=$ coeficiente de variação. Fonte: Autores.

Na Figura 1 é possível observar que as diferentes concentrações de cama de aviário aplicadas no solo influenciaram positivamente a altura das mudas de $R$. acuminata. Ao analisarmos a resposta da variável altura em função da dose aplicada de cama de aviário foi observado comportamento quadrático, que alcançou altura máxima estimada de 38,97 cm na dose estimada de $24,82 \%$ de cama de aviário. Desta forma, foi notório o efeito positivo da mistura da cama de aviário na composição do substrato, tornando-o mais fértil e com características desejáveis ao desenvolvimento das mudas nas diferentes concentrações que foram produzidas. Malcher et al. (2013) avaliaram níveis de matéria orgânica para a formação de mudas de biribazeiro (Rollinia mucosa) e constataram que a adição de 20 e $30 \%$ de cama de aviário ao solo obtiveram os melhores resultados para a altura das mudas. Carvalho et al. (2004) avaliaram o efeito de doses percentuais de cama de frango na produção de mudas de abieiro (Pouteria caimito) e observaram que as doses de 10 e $20 \%$ possibilitaram o maior crescimento desse vegetal. Pereira et al. (2010) avaliaram mudas de tamarindeiro produzidas em diferentes níveis de matéria orgânica adicionada ao substrato e observaram que as mudas produzidas no substrato que continham 20, 30 e 40\% obtiveram maior altura.

Figura 1. Altura de mudas de $R$. acuminata formadas com substrato contendo solo e diferentes concentrações de cama de aviário. Belém - PA.

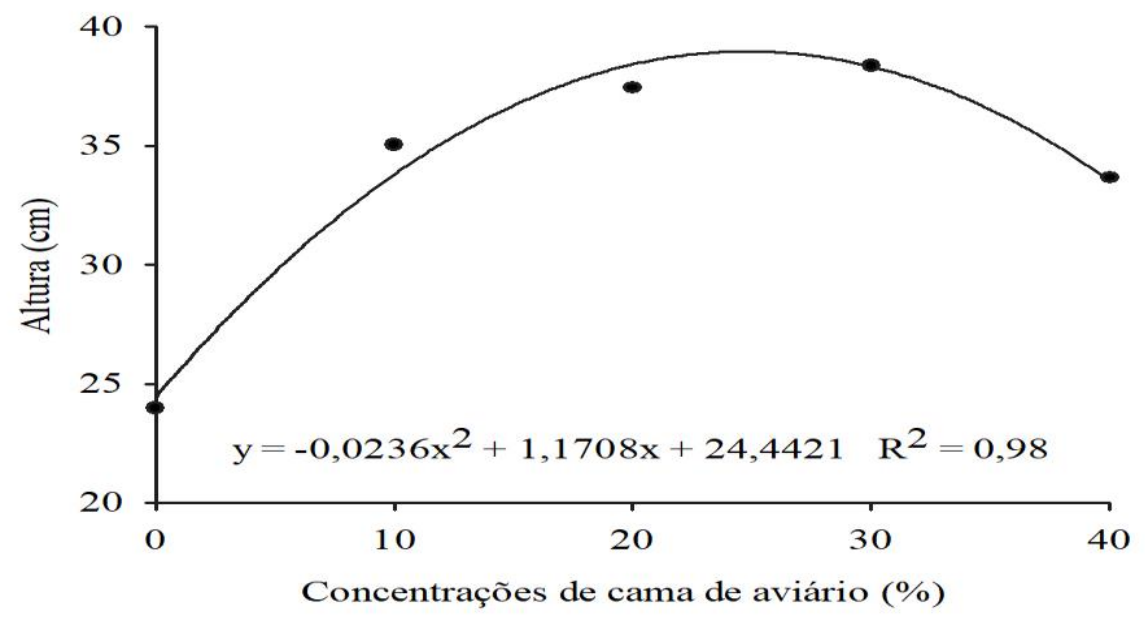

Fonte: Autores. 
Para a variável diâmetro do coleto das mudas foi observado comportamento quadrático (Figura 2). Também foi observado que a concentração de cama de aviário influenciou positivamente no desenvolvimento das mudas de $R$. acuminata; assim, o diâmetro máximo estimado foi de $8,51 \mathrm{~mm}$ na dose estimada de 21,90\% de cama de aviário. Foi notório a influência que a cama de aviário proporcionou ao desenvolvimento das mudas, sendo uma fonte orgânica de nutrientes para a composição do substrato. Esses resultados estão de acordo com os observados por Frade Junior et al. (2011) que estudaram substratos de resíduos orgânicos para produção de mudas de ingazeiro (Inga edulis Mart.) e observaram que a mistura de cama de aviário $(10,20$ ou $30 \%)$ ao substrato promoveu as melhores médias para o diâmetro do coleto das mudas, ainda que não tenham diferido do tratamento que não continha cama de aviário. A cama de aviário associada a casca de amendoim e/ou a mucilagem de sisal, que são materiais que proporcionam boas características físicas, se mostra como boa composição para substrato (Lima et al., 2006). Esses autores também afirmam que o substrato composto por solo, casca de amendoim, cama de aviário e mucilagem de sisal propiciou o melhor crescimento em quase todas as variáveis analisadas.

Figura 2. Diâmetro do coleto de mudas de R. acuminata formadas com substrato contendo solo e diferentes concentrações de cama de aviário. Belém - PA.

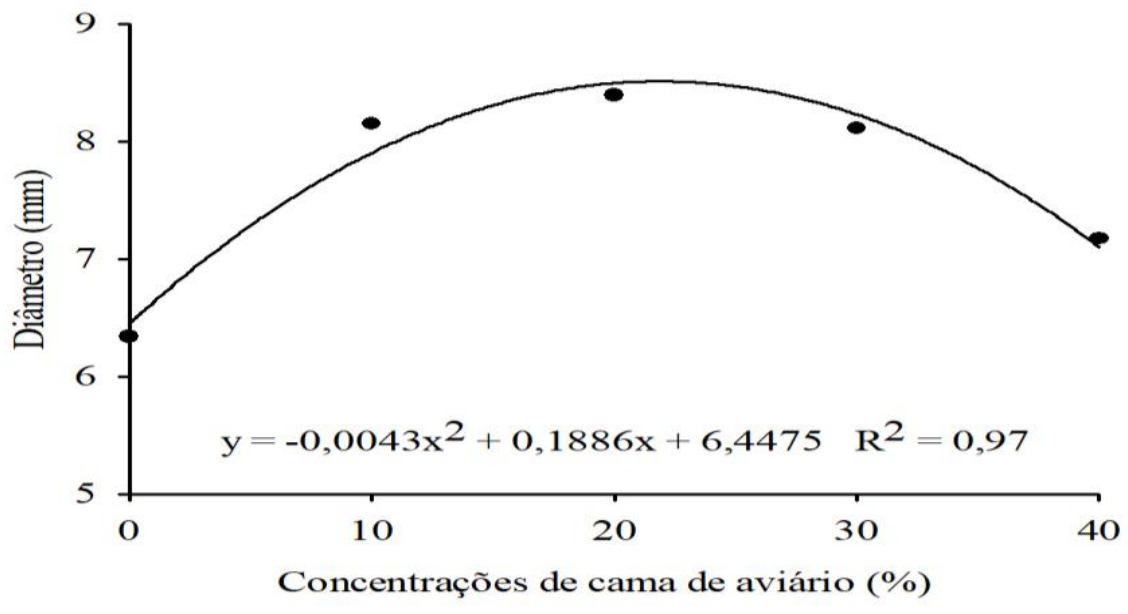

Fonte: Autores.

Na resposta da variável número de folhas em função da dose aplicada de cama de aviário (Figura 3), observou-se comportamento quadrático, que alcançou máxima estimada de 28,52 unidades por muda ${ }^{-1}$ na dose estimada de $33,86 \%$ de cama de aviário misturada ao solo. Assim, pode-se entender que até a dose citada, contida no substrato, influenciou positivamente a emissão de folhas nas mudas e a partir dessa dose o efeito foi de decréscimo. Tavares et al. (2014) avaliaram produção de mudas de murucizeiro (Byrsonima crassifolia (L.) H.B.K) com diferentes concentrações de nutrientes e constaram que o maior número de folhas por planta $(17,53)$ foi obtido na dose de $30 \%$ de cama de aviário misturado ao solo. Nogueira et al. (2019) estudando diferentes fontes e proporções de adubo orgânico na produção de mudas de açaí-solteiro, observaram ajuste por equações de regressão quadráticas para a variável número de folhas e que a cama de aviário misturada ao solo atingiu os maiores valores nas proporções entre 33\% e 41\%, com uma média de 5,03 folhas. 
Figura 3. Número de folhas de mudas de R. acuminata formadas com substrato contendo solo e diferentes concentrações de cama de aviário. Belém - PA.

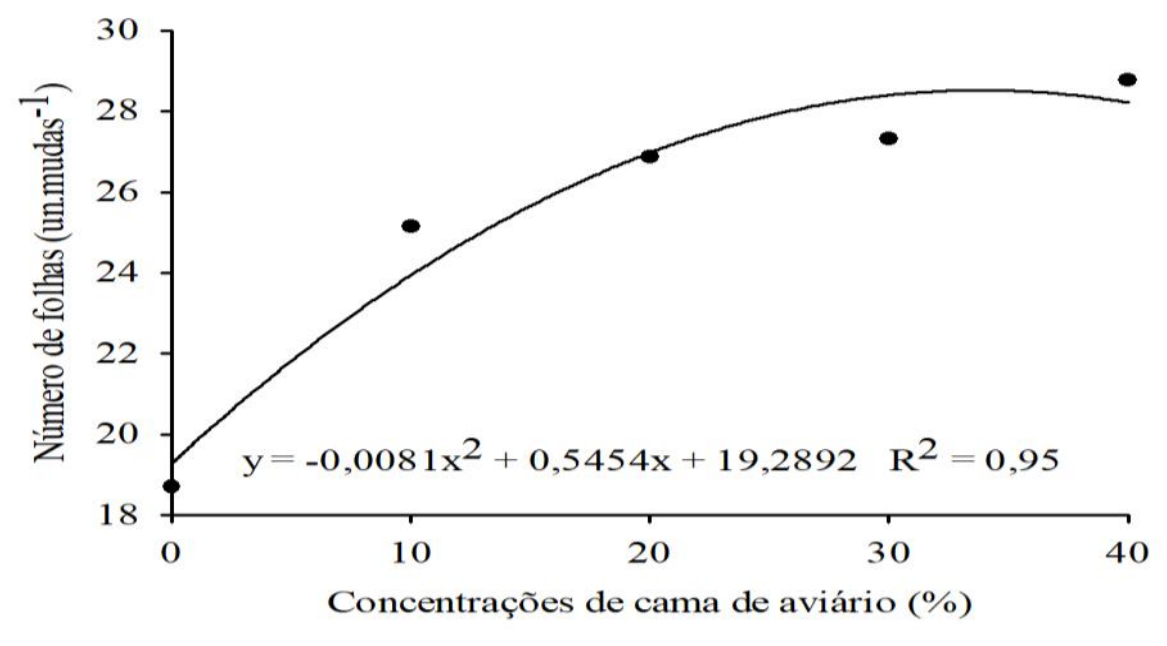

Fonte: Autores.

Na Figura 4 é possível observar que as concentrações de cama de aviário na composição do substrato influenciaram positivamente na formação das mudas de $R$. acuminata, o que resultou em mudas vigorosas prontas para serem plantadas no local definitivo. Na resposta da variável massa seca da parte aérea em função da dose aplicada de cama de aviário observou-se comportamento quadrático, que alcançou peso máximo estimado de 24,21 g na dose estimada de 27,75\% de cama de aviário misturada ao solo. Em estudo com a Mimosa setosa Bent, Faria et al. (2016), observaram que a mistura de 35\% de cama de aviário ao substrato proporcionou o maior peso de massa seca da parte aérea. Em contraste ao observado nesse trabalho, Torres et al. (2011) estudando o desenvolvimento de mudas de pinhão manso sob diferentes doses de cama de frango no substrato, observaram que com o aumento das doses de cama de aviário na composição do substrato houve decréscimo na massa seca da parte aérea das mudas.

Figura 4. Massa seca da parte aérea de mudas de R. acuminata formadas com substrato contendo solo e diferentes concentrações de cama de aviário. Belém - PA.

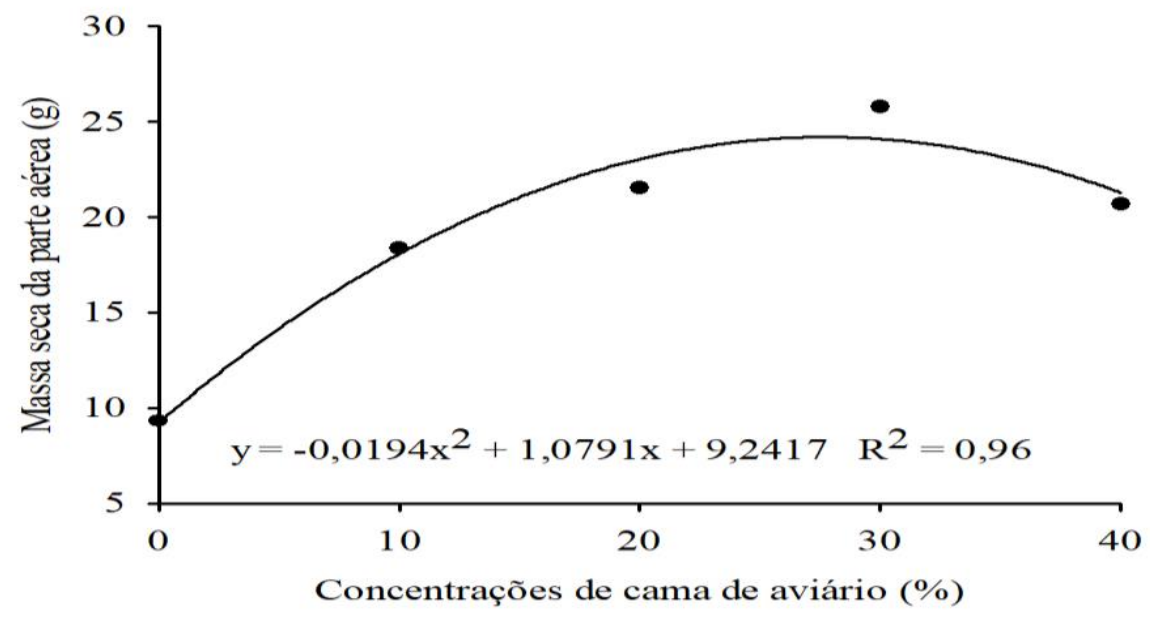

Fonte: Autores. 
Para a variável massa seca da raiz (Figura 5) é possível observar que as concentrações de cama de aviário aplicadas no solo influenciaram positivamente na formação das mudas de $R$. acuminata. Na resposta desta variável se observou comportamento quadrático, que alcançou peso máximo estimado de 12,11 g na dose estimada de 21,84\% de cama de aviário na composição do substrato. Faria et al. (2016) avaliando substratos alternativos na produção de mudas de Mimosa setosa Benth, observaram que a mistura de $25 \%$ e $35 \%$ de cama de aviário ao substrato proporcionou o maior peso de massa seca do sistema radicular das mudas. Lima et al. (2006) estudando substratos para produção de mudas de mamoneira compostos por misturas de cinco fontes de matéria orgânica, observaram a adição de $25 \%$ de cama de aviário juntamente com outras fontes de matéria orgânica proporcionaram a muda maior peso seco do sistema radicular.

Figura 5. Massa seca da raiz de mudas de $R$. acuminata formadas com substrato contendo solo e diferentes concentrações de cama de aviário. Belém - PA.

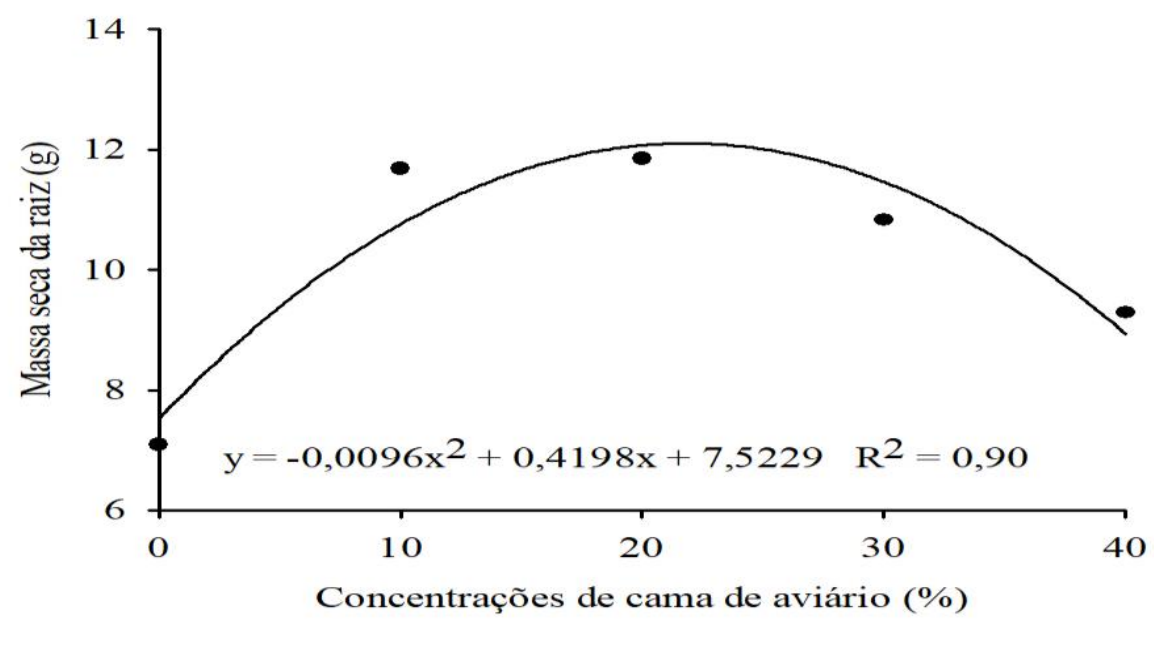

Fonte: Autores.

Para a variável massa seca total (Figura 6) é possível observar que as concentrações de cama de aviário aplicadas no solo influenciaram positivamente na formação das mudas de $R$. acuminata. Na resposta desta variável se observou comportamento quadrático, que alcançou peso máximo estimado de 36,09 g na dose estimada de 25,79\% de cama de aviário na mistura que compôs o substrato. Nogueira et al. (2019) estudando as diferentes fontes e proporções de adubo orgânico na produção de mudas de açaí solteiro, observaram que as mudas produzidas sob dosagens entre $11 \%$ e $14 \%$ alcançaram média estimada de 7,5 $\mathrm{g}$ de massa seca total. 
Figura 6. Massa seca total de mudas de R. acuminata formadas com substrato contendo solo e diferentes concentrações de cama de aviário. Belém - PA.

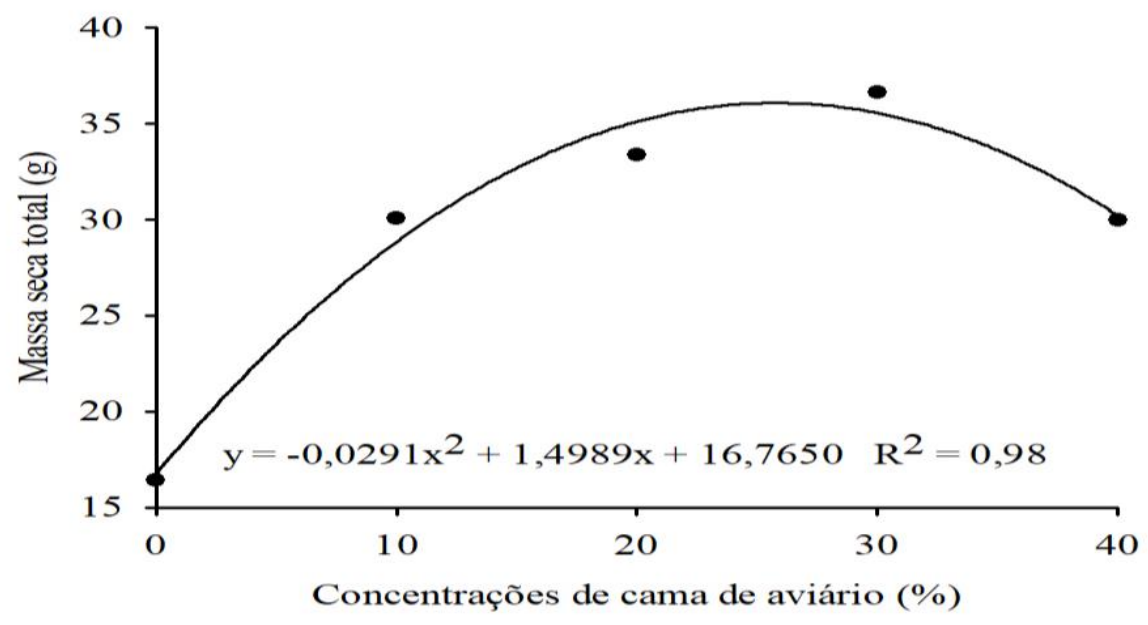

Fonte: Autores.

Ocorreu comportamento quadrático para a variável Índice de Qualidade de Dickson (Figura 7). Foi observado IQD máximo estimado de 5,48 g na dose estimada de 22,64\% de cama de aviário misturada ao solo, mostrando que as mudas produzidas sob dosagens na faixa entre $20 \%$ a $30 \%$ foram as mais vigorosas e com qualidade para serem plantadas em campo sem que haja comprometimento no seu desenvolvimento, observando para isso os manejos recomendados para a cultura em questão. O IQD é considerado bom indicador da qualidade das mudas, uma vez que no seu cálculo são considerados a robustez e o equilíbrio da distribuição da biomassa na muda (Fonseca et al., 2002). Como o IQD leva em consideração grandezas observadas no desenvolver das mudas, os resultados podem sofrer variações sendo que um dado resultado observado em uma dada pesquisa pode não ser observado em outra.

Figura 7. Índice de qualidade de Dickson de mudas de R. acuminata formadas com substrato contendo solo e diferentes concentrações de cama de aviário. Belém - PA.

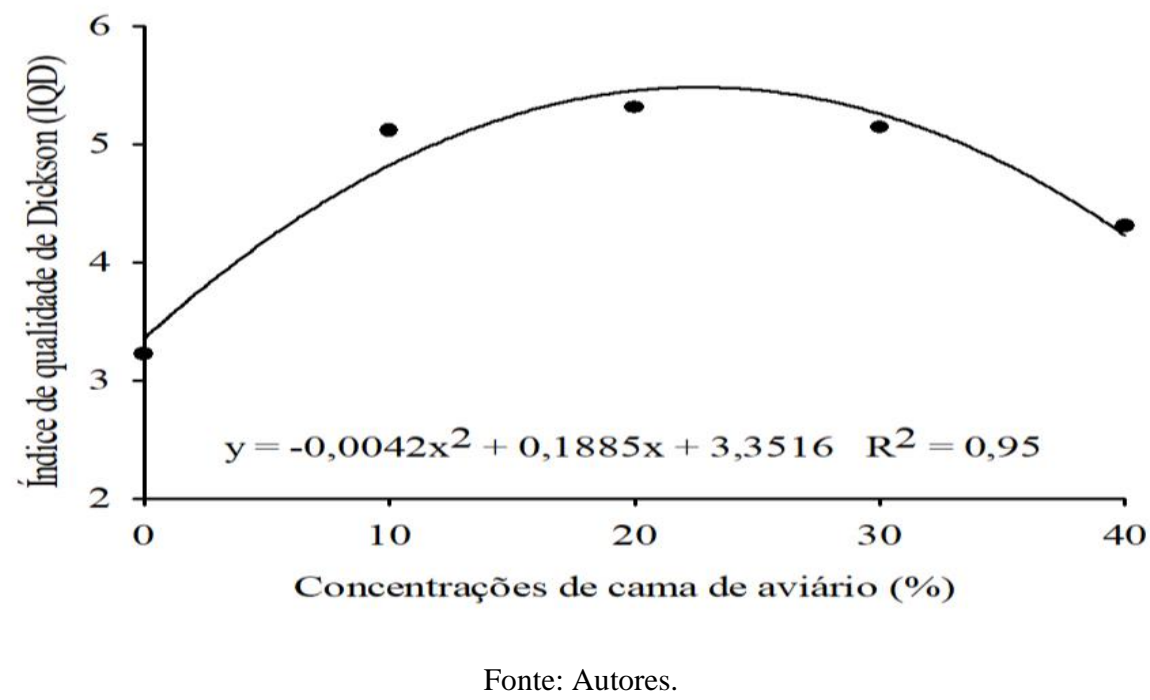

A cama de frango é uma boa fonte de nutrientes, especialmente de nitrogênio, e quando manejada adequadamente, pode suprir parcial ou totalmente, o fertilizante químico. Além do benefício como fonte de nutrientes, o seu uso adiciona 
matéria orgânica que melhora os atributos físicos do solo, aumenta a capacidade de retenção de água, reduz a erosão, melhora a aeração e cria um ambiente mais adequado para o desenvolvimento da flora microbiana do solo (Blum et al., 2003). Com isso, o sistema radicular da muda consegue se desenvolver melhor e, consequentemente, melhora o desenvolvimento da parte aérea formando mudas de elevada qualidade e com capacidade de sobrevivência quando plantadas em local definitivo.

\section{Conclusão}

A produção de mudas de $R$. acuminata é potencializada pela adição da matéria orgânica formando mudas de qualidade para serem levadas ao campo.

A adição de cama de aviário nas concentrações entre $20 \%$ e $30 \%$ na composição do substrato proporcionaram as melhores médias para os parâmetros morfológicos e IQD nas mudas.

\section{Referências}

Blum, L. E. B, Amarante, C. V. T., Güttler, G., Macedo, A. F., Kothe, D., Simmler, A., Prado, G., \& Guimarães, L. (2003). Produção de moranga e pepino em solo com incorporação de cama aviária e casca de pinus. Horticultura Brasileira, 21(4), 627-631. Recuperado de https://www.horticulturabrasileira.com.br/index.php?option=com_content\&view=article\&id=5\&Itemid=121\&artigo=http://www.horticulturabrasileira.com.br/ images/stories/21_4/20032149.pdf

Carvalho, J. E. U., Júnior, J. F., Müller, C. H., Teixeira, L. B., \& Dutra, S. (2004). Efeito de doses percentuais de cama de frango na produção de mudas de abieiro. Belém, PA.

Cavalcante, P. $\quad$ B. (2010). Frutas comestíveis na Amazônia. (7a ed.). Belém: Museu Paraense Emílio Goeldi.

David, M. A., Mendonca, V., Reis, L. L., Silva, E. A., Tosta, M. S., \& Freire, P. A. (2008). Efeito de doses de superfosfato simples e de matéria orgânica sobre o crescimento de mudas de maracujazeiro 'amarelo'. Pesquisa Agropecuária Tropical, 38(3), 147-152. Recuperado de https://revistas.ufg.br/pat/article/view/3783

Dickson, A., Leaf, A. L., \& Hosner, J. F. 1960. Quality appraisal of while spruce and white pine seedling stock in nurseries. Forestry Chronicle, 36(1), 10-13. doi.org/10.5558/tfc36010-1

Faria, J. C. T., Caldeira, M. V. W., Delarmelina, W. M., \& Rocha, R. L. F. (2016). Substratos alternativos na produção de mudas de Mimosa setosa Benth. Ciência Florestal, 26(4), 1075-1086. Recuperado de https://periodicos.ufsm.br/cienciaflorestal/article/view/24996/pdf

Ferreira, D. F. (2011). Sisvar: um sistema computacional de análise estatística. Ciência e Agrotecnologia, 35(6), 1039-1042. doi.org/10.1590/S141370542011000600001

Fonseca, E. P., Valéri, S. V., Miglioranza, E., Fonseca, N. A. N., \& Couto, L. 2002. Padrão de qualidade de mudas de Trema micrantha (L.) Blume, produzidas sob diferentes períodos de sombreamento. Revista Árvore, 26(4), 515-523. doi.org/10.1590/S0100-67622002000400015

Frade Junior, E. F., Araújo, J. A., Silva, S. B., Moreira, J. G. V., \& Souza, L. P. (2011). Substratos de resíduos orgânicos para produção de mudas de ingazeiro (Inga edulis Mart) no Vale do Juruá - Acre. Enciclopédia Biosfera, 7(13), 959-969. Recuperado de https://conhecer.org.br/ojs/index.php/biosfera/article/view/4183

Lima, I. M. O., Silva Júnior, J. S., Costa, E., Cardoso, E. D., Binotti, F. F. S., \& Jorge, M. H. A. (2016). Diferentes substratos e ambientes protegidos para o crescimento de mudas de maracujazeiro amarelo doce. Revista de Agricultura Neotropical, 3(4), 39-47. doi.org/10.32404/rean.v3i4

Lima, R. L. S., Severino, L. S., Silva, M. I. L., Jerônimo, J. F., Vale, L. S., \& Beltrão, N. E. M. (2006). Substratos para produção de mudas de mamoneira compostos por misturas de cinco fontes de matéria orgânica. Ciência e Agrotecnologia, 30(3), 474-479. doi.org/10.1590/S1413-70542006000300013

Malcher, D. J. P., Nascimento, W. M. O., Mendes, N. V. B., \& Tavares, R. F. M. (2013). Níveis de matéria orgânica para formação de mudas de biribazeiro. In: Seminário de Iniciação Científica, 17., Seminário de Pós-graduação da Embrapa Amazônia Oriental, 1., 2013, Belém, PA. Anais. Belém, PA: Embrapa Amazônia Oriental.

Mendes, N. V. B., Nascimento, W. M. O., Tavares, R. F. M., \& Malcher, D. J. P. (2014). Diferentes doses de cama de aviário para formação de mudas de açaído-amazonas (Euterpe Precatória Mart.). In: Encontro Amazônico de Agrárias, 6., 2014, Belém, PA. Anais. Belém, PA: Universidade Federal Rural da Amazônia. 
Research, Society and Development, v. 10, n. 11, e170101119403, 2021

(CC BY 4.0) | ISSN 2525-3409 | DOI: http://dx.doi.org/10.33448/rsd-v10i11.19403

Mendes, N. V. B., Nascimento, W. M. O., Lima, D. C., Tavares, R. F. M., \& Malcher, D. J. P. (2020). Tratamentos pré-germinativos em sementes e emergência de plântulas de Garcinia acuminata. Research, Society and Development, 9(12), e11591210758. doi.org/10.33448/rsd-v9i12.10758

Mesquita, E. F., Chaves, L. H. G., Freitas, B. V., Silva, G. A., Sousa, M. V. R., \& Andrade, R. (2012). Produção de mudas de mamoeiro em função de substratos contendo esterco bovino e volumes de recipientes. Revista Brasileira de Ciências Agrárias, 7(1), 58-65. doi:10.5039/agraria.v7i1a1448

Nascimento, W. M. O., Carvalho, J. E. U., \& Müller, C. H. (2002). Caracterização morfológica da semente e da plântula de bacurizinho (Rheedia acuminata (Ruiz et Pav.) Plachon et Triana - Clusiaceae). Revista Brasileira de Fruticultura, 24(2), 555-558. doi.org/10.1590/S0100-29452002000200055

Nogueira, R. S., Lunz, A. M. P., Araújo, C. S., Andrade Neto, R. C., \& Carvalho, P. H. S. (2020). Diferentes fontes e proporções de adubo orgânico na produção de mudas de açaí-solteiro. In: Seminário de Iniciação Científica e Pós-Graduação da Embrapa Acre, 2., 2020, Rio Branco, AC. Anais. Rio Branco: Embrapa Acre.

Oliveira, F. L., Guerra, J. G. M., Almeida, D. L., Ribeiro, R. L. D., Silva, E. D., Silva, V. V., \& Espindola, J. A. A. (2008). Desempenho de taro em função de doses de cama de aviário, sob sistema orgânico de produção. Horticultura Brasileira, 26(2), 149-153. doi.org/10.1590/S0102-05362008000200004

Pereira, P. C., Melo. B., Freitas, R. S., Tomaz, M. A., \& Freitas, C. J. P. (2010). Mudas de tamarindeiro produzidas em diferentes níveis de matéria orgânica adicionada ao substrato. Revista Verde, 5(3), 152-159. Recuperado de https://www.gvaa.com.br/revista/index.php/RVADS/article/view/318

Tavares, R. F. M., Nascimento, W. M. O., Malcher, D. J. P, Mendes, N. V. B. 2014. Produção de mudas de murucizeiro (Byrsonima crassifolia (L.) H.B.K.) com diferentes concentrações de nutrientes. In: Seminário de Iniciação Científica, 18., Seminário de Pós-Graduação da Embrapa Amazônia Oriental, 2., 2014, Belém, PA. Anais. Belém, PA: Embrapa Amazônia Oriental.

Torres, G. N., Vendruscolo, M. C., Santi, A., Soares, V. M., \& Pereira, P. S. X. (2011). Desenvolvimento de mudas de pinhão manso sob diferentes doses de cama de frango no substrato. Revista Verde, 6(4), 244-250. Recuperado de https://www.gvaa.com.br/revista/index.php/RVADS/article/view/783

Yamanishi, O. K., Fagundes, G. R., Machado Filho, J. A., \& Valone, G. V. (2004). Efeito de diferentes substratos e duas formas de adubação na produção de mudas de mamoeiro. Revista Brasileira de Fruticultura, 26(2), 276-279. doi.org/10.1590/S0100-29452004000200023

Van den Berg, M. E. (1979). Revisão das espécies brasileiras do gênero Rheedia L. (Guttiferae). Acta Amazônica, 9(1), 43-74. doi.org/10.1590/1809-43921979091043 